\title{
Influence of food availability on the spatial distribution of juvenile fish within soft sediment nursery habitats
}

\author{
Tableau Adrien ${ }^{1,2}$, Brind'Amour Anik ${ }^{2}$, Woillez Mathieu ${ }^{3}$, Le Bri $\mathrm{H}^{1}$ \\ ${ }^{1}$ AGROCAMPUS OUEST, UMR985 ESE Ecologie et santé des écosystèmes, 65 rue de St Brieuc, CS \\ 84215, 35042 Rennes Cedex, France \\ ${ }^{2}$ Ifremer, EMH, rue de l'île d'Yeu, BP 21105, 44311 Nantes Cedex 03, France \\ ${ }^{3}$ Ifremer, LBH, ZI de la Pointe du Diable, CS 10070, 29280 Plouzané, France
}

\begin{abstract}
:
Soft sediments in coastal shallow waters constitute nursery habitats for juveniles of several flatfishes. The quality of a nursery is defined by its capacity to optimize the growth and the survival of juvenile fish. The influence of biotic factors, such as food availability, is poorly studied at the scale of a nursery ground. Whether food availability limits juvenile survival is still uncertain. A spatial approach is used to understand the influence of food availability on the distribution of juvenile fish of various benthic and demersal species in the Bay of Vilaine (France), a productive nursery ground. We quantified the spatial overlap between benthic macro-invertebrates and their predators (juvenile fish) to assess if the latter were spatially covering the most productive areas of the Bay. Three scenarios describing the shapes of the predator-prey spatial relationship were tested to quantify the strength of the relationship and consequently the importance of food availability in determining fish distribution. Our results underline that both food availability and fish densities vary greatly over the nursery ground. When considering small organisational levels (e.g., a single fish species), the predator-prey spatial relationship was not clear, likely because of additional environmental effects not identified here; but at larger organisational level (the whole juvenile fish community), a strong overlap between the fish predators and their prey was identified. The evidence that fish concentrate in sectors with high food availability suggests that either food is the limiting factor in that nursery or/and fish display behavioural responses by optimising their energetic expenditures associated with foraging. Further investigations are needed to test the two hypotheses and to assess the impact of benthic and demersal juvenile fish in the food web of coastal nurseries.
\end{abstract}




\section{Graphical abstract}

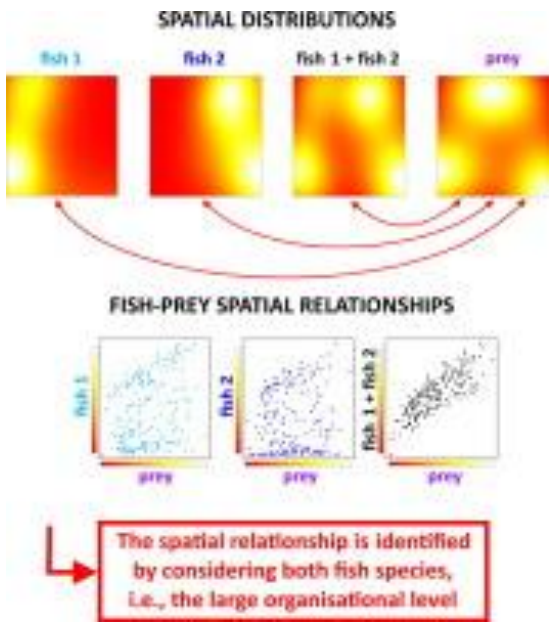

\section{Highlights}

This study provides an evaluation of the influence of the food availability on the spatial distribution of juvenile fish within a coastal nursery; It compares the spatial match between the distribution of the predators and their prey at different organisational levels (species, morphological group, and community); Juvenile fish density was associated to the prey spatial distribution and would apply a strong predation pressure at the scale of the Bay; The fish community is apparently the most relevant organisational level for addressing nurseries food availability issues.

Keywords: Predator-prey relationship ; Nursery habitat ; Flatfish ; Demersal fish ; Benthic invertebrates ; Spatial overlap ; Food limitation 


\section{INTRODUCTION}

Soft substrates in coastal shallow waters constitute nursery habitats for juveniles of several flatfishes of commercial interest (e.g., Solea solea, Pleuronectes platessa) and also of other demersal species (e.g., Trisopterus luscus, Merlangius merlangus) (Gibson, 1994; Elliott and Hemingway, 2002; Able, 2005; Franco et al., 2006). For most of those fishes, the juvenile phase is characterised by high growth and mortality rates, followed by a migration toward deeper zones at sexual maturity (Dorel et al., 1991; Le Pape et al., 2003). Thus, the juvenile phase represents a bottleneck with regard to recruitment, making a large proportion of commercial species highly dependent on coastal habitats to complete their life cycle (Seitz et al., 2014).

The total number of juvenile fish produced yearly by all nursery habitats related to a fish stock shows large temporal variability (e.g., Rijnsdorp et al., 1992). These variations are notably influenced not only by the surface area but also the quality of the nursery grounds (Rijnsdorp et al., 1992; Rochette et al., 2010) and by environmental fluctuations such as those in temperature (van der Veer et al., 2000), salinity (Pasquaud et al., 2012), and river discharge (Le Pape et al., 2003; Kostecki et al., 2010). Within a nursery area, high spatial and interannual variations of juvenile density are also observed (e.g., Dorel et al., 1991; Rogers, 1992; Kopp et al., 2013). The variations are directly related to the complexity and spatial heterogeneity in the physico-chemical properties of these coastal habitats; a main reason is that physico-chemical properties can exceed the physiological tolerance of certain juvenile fishes (e.g., hypoxic stress, salinity or temperature tolerance). Predation and food availability, although less often studied (Johnson et al., 2013), are two main biotic factors impacting the growth, survival, and spatial distribution of juveniles within nursery grounds (Gibson, 1994).

Competition for food is expected to regulate growth and survival rates of juveniles but the impact level of food availability is still widely controversial (Le Pape and Bonhommeau, 2015). Some authors argue that food limits the carrying capacity of nurseries (e.g., Gibson, 1994; Nash and Geffen, 2000; van der Veer et al., 2010), whereas others strongly argue that there is enough food for all the species in nurseries (e.g., van der Veer and Witte, 1993; Hampel et al., 2005; Vinagre and Cabral, 2008). These competing viewpoints lead to two different expectations regarding the distribution of juvenile fish. (1) In the case of food limitation, juvenile fish are expected to be more concentrated in sectors where prey 
are abundant; indeed, the mobility of benthic invertebrates being negligible in comparison to benthic and demersal juvenile fish, starved juvenile fish should migrate towards nursery sectors with higher food availability (the order of magnitude of potential daily distances travelled by juvenile flatfish is about 1 km: Berghahn, 1987; Burrows et al., 1994, 2004; Gibson et al., 1998; Morrison et al., 2002, Vinagre et al., 2006; Le Pape and Cognez, 2015). Therefore, juvenile fish distribution should follow the feeding potentials of a nursery habitat. (2) Where food is not limiting, we expect a weak (or no) spatial relationship between fish and their prey. Indeed, because food is in excess, the influence of food quantity on fish distribution should be minimal. Juvenile fish should be more responsive to food quality and select a nursery sector more for the composition of its prey community than for the total food availability. In this case, food factor may be less determining than local variations of abiotic factors such as temperature or granulometry.

Liebig's law of the minimum states that ecological processes, such as the growth of juveniles, may be influenced by a multitude of factors, but are only controlled by the scarcest resource (Cade et al., 1999; Hiddink and Kaiser, 2005); e.g., oxygen concentration or food availability (Gibson, 1994). The factors are thus not additive but multiplicative; indeed, only one unfavourable factor among all is enough to penalise the response. This concept can be broadened to give a general framework within which to discuss the food limitation hypothesis (Johnson et al., 2012) in nurseries, by characterizing the spatial relationships between the fish and their prey. Three scenarios are thus expected (Fig. 1). (1) In the first scenario, the relationship between predators and prey is highly predictive; high food densities involve necessarily high juvenile fish densities. If the other influencing factors are independent from predator and prey distributions, food availability will likely drive the behaviour of juveniles, either because of a food limitation effect, or because these predators optimise their energetic expenditures associated with foraging (Rose and Leggett, 1990). It is also possible that unmeasured abiotic factors define both predators and prey distributions; therefore, this first scenario must be considered along with available information on abiotic factors influencing benthic communities within the nursery. (2) In the second scenario, there is no predictive relationship between the fish and their prey. The juveniles are found in high densities even in sectors where prey abundance is relatively low. This suggests that food seems to be in excess and consequently is not a limiting factor. (3) In the third scenario, high densities of juveniles are restricted to areas of high prey densities, suggesting 
either food limitation or a behavioural response of the predator optimising its probability of catching a prey. But, unlike the first scenario, low densities of juveniles in sectors with high prey abundance indicate that other unmeasured factors are potentially limiting (Johnson et al., 2012). This scenario also suggests that the factor(s) determining fish density vary from one sector to another.

The present study aims to assess the influence of benthic prey availability on the spatial distribution of benthic and demersal juvenile fish in a nursery ground, the Bay of Vilaine (France). It was conducted in two steps. We first explored the influence of the organisational level of predators (species level, morphological group level, and community level) on the predator-prey relationship. Considering several benthic and demersal juvenile fishes together to study the predator-prey relationship is relevant because they display similar prey spectra (Piet et al., 1998). We secondly tested the three aforementioned scenarios by quantifying the spatial correspondence between the abundances of juveniles and their prey, in order to infer the regulation potential of food availability on juvenile fish distribution in the studied nursery.

\section{MATERIALS AND METHODS}

\subsection{Study site}

The Bay of Vilaine (Fig. 2) is a soft-bottom ground used as a nursery by several benthic and demersal fishes of commercial interest (Desaunay et al., 1981; Dorel et al., 1991). It has been studied for more than 30 years, producing valuable knowledge on its fish (Marchand,1991; Le Pape et al., 2003; Nicolas et al., 2007; Kopp et al., 2013) and benthic invertebrate communities (Le Bris and Glemarec, 1995; Brind'Amour et al., 2009, 2014). Given such data and knowledge-rich context, the Bay constitutes a relevant framework to analyse predator-prey relationships. The studied area covers the subtidal zone located from 5-30 m depth and is mostly composed of fine soft sediments, from muds to sandy muds (Le Bris and Glemarec, 1995). All samples obtained in the current study were collected on these types of sediment (Fig. 2).

\subsection{Biological data}

The Bay of Vilaine was sampled in late summer of 2008 with two devices: a beam trawl targeting the benthic and demersal fish community, and a grab targeting their prey, i.e., the benthic macro- 
invertebrate community. The beam trawl was $2.9 \mathrm{~m}$ wide and $0.5 \mathrm{~m}$ high, with a $20 \mathrm{~mm}$ stretchedmesh net in the cod-end. Each haul was performed with the beam trawl towed at approximately 3 knots for 15 min on stations displaying homogeneous sediment and water depth, covering a mean surface of $4000-4500 \mathrm{~m}^{2}$. Total catch in each haul was weighed and fish were identified, counted, and weighed by species. The device used to sample the macro-invertebrate community was a $0.1 \mathrm{~m}^{2}$ van Veen (1933) grab. Once aboard, grab samples were immediately rinsed on a $1 \mathrm{~mm}$-mesh sieve on the boat deck and the retained fraction (i.e., material $\geq 1 \mathrm{~mm}$ ) collected in zipper bags and fixed with buffered formalin solution to a final concentration of $7 \%$. In the laboratory, samples were rinsed with water and then fractionated using a column of 5 successive sieves of different mesh sizes from $1 \mathrm{~mm}$ to $16 \mathrm{~mm}$ square mesh, according a geometric progression. The benthic invertebrates sorted from each mesh size were stored in a $70 \%$ ethanol solution, identified to the lowest taxonomic level possible, and weighed using an analytical balance sensitive to $1 \mathrm{mg}$ (Model Scout Pro SPU123, Ohaus Corporation, Pine Brook, NJ USA).

The locations of grab and trawl stations did not perfectly match each other, spatially. Therefore, the present study only focuses on the sector of the Bay of Vilaine in which both fish and benthic macroinvertebrates were sampled; this sector was delimited by the polygon on Fig. 2 .

\subsubsection{Fish selection}

Forty two hauls targeting the fish community were performed inside the study zone (Fig. 2). Thirty one fish species were identified and corresponded to a total catch of $216 \mathrm{~kg}$. Most catches corresponded to benthic and demersal juvenile fishes belonging to the age groups 0 and 1 ( $G 0$ and $G 1$ ). Based on the literature regarding feeding habits, and upon gut contents analyses (Tableau et al., 2015), we selected for additional analysis the fish species that fed mainly on benthic macro-invertebrates. These fish species represented $71 \%$ of the catches: three flatfishes (Solea solea, Dicologlossa cuneata and Pleuronectes platessa) and four roundfishes (Callionymus lyra, Trisopterus luscus, Merlangius merlangus, Mullus surmuletus). Eight other main species corresponding to $28 \%$ of the catches were excluded from the study because benthic macro-invertebrates were not the main part of their diet. We also excluded the 16 other fish species from our analyses as their total abundance contributed to only $1 \%$ of the total catches. 
Within the seven selected species, we focused especially upon individuals of sizes that can feed on macro-invertebrates (Table 1). Indeed, given the fast growth of these juvenile fishes, their feeding abilities evolve with their size and diet shifts can be observed (Juanes and Conover, 1994). For most G0 juveniles, a shift from meiofauna to small macrofauna is observed shortly after the metamorphosis (Marchand, 1991; Rogers, 1994; Amara et al., 2001; Darnaude et al., 2001). According to 750 gut content analyses on P. platessa, T. Iuscus, C. lyra, S. solea, and D. cuneata (sampled in 2008 in the Bay of Vilaine), we selected the juveniles that fed mainly on macro-invertebrates. For the three former, we defined this as a size of $7 \mathrm{~cm}$ and greater, for which meiofauna represented less than $40 \%$ of prey items (arbitrary threshold). For S. solea and D. cuneata, no individual below $7 \mathrm{~cm}$ was collected and gut analyses concluded that all individuals always fed mainly on benthic macrofauna, a result consistent with the other fishes. In the absence of gut analysis for the two remaining roundfishes, $M$. merlangus and M. surmuletus, we also used the $7 \mathrm{~cm}$ threshold of $T$. luscus and $C$. lyra for them. During their growth, the diet of the studied juvenile fishes may also shift from macrofauna to ichtyofauna. For instance, Hamerlynck and Hostens (1993) found a shift from macrofauna to ichtyofauna at $10 \mathrm{~cm}$ for $T$. luscus and M. merlangus. In the Bay of Vilaine, ichtyofauna was observed in 7 out of 272 gut contents of $T$. luscus (5-15 cm-length) analysed. Therefore, by conservative standard, the chosen threshold for this shift was set at $15 \mathrm{~cm}$. Such a shift was not observed for the other species considered in this study. The threshold and ceiling sizes are displayed in Table 1.

Unlike the dominant roundfishes considered in this study ( $T$. luscus and M. merlangius, respectively 64 and $23 \%$ of all roundfish by weight), juvenile flatfish (dominated by S. solea; $69 \%$ of all flatfish by weight) fed exclusively on benthic macro-invertebrates (e.g., Desmarchelier, 1986; Hamerlynck and Hostens, 1993; Amara et al., 2001, 2004). If fish were distributed in correspondence with their prey availability, we would expect flatfish to have a stronger relationship with the macro-invertebrate distribution than roundfish. To test this hypothesis, predators were considered at three different organisational levels: a single species, considering only S. solea; a morphological group that considered the entire sampled flatfish community; and the largest bentho-demersal community composed of species feeding on macro-invertebrates, considering all of the selected fishes. 


\subsubsection{Benthic macro-invertebrate community}

Thirty four stations were sampled in soft sediments inside the study zone; three replicate grabs were taken at each station. A total of 160 taxa were identified (Tableau et al., 2015). The density of benthic macro-invertebrates was estimated by pooling the replicates (Gallardo, 1965; Eleftheriou and Mclntyre, 2005).

Among the 160 taxa collected, 95 were considered to be prey for the selected fish community (Tableau et al., 2015). They represented $96 \%$ of the collected benthos by weight. Although biomass is commonly used to describe the distribution of benthic invertebrates (e.g., Collie, 1987; Hansson et al., 1996; Vinagre and Cabral, 2008), such a metric is a biased proxy of the energy available for predators (Brey et al., 2010; Tableau et al., 2015). Unlike fish species, the energy density can be very different from one benthic invertebrate species to another because of the presence of a shell for some of them. For instance, for a given weight, the energy of $1 \mathrm{~g}$ of the bivalve Abra alba (energy density: $1.1 \mathrm{~kJ} / \mathrm{g}$ ) is 5 times less than the energy estimated for $1 \mathrm{~g}$ of the polychaete Owenia fusiformis (energy density: 5.2 $\mathrm{kJ} / \mathrm{g})$.

We thus converted biomass values into energy values using Brey's database gathering energy density values $\left({\left.\mathrm{KJ} . \mathrm{g}^{-1}\right)}\right.$ (Brey, 2001). Moreover, a prey is more or less accessible to a predator depending on its ability to hide or escape. It is thus relevant to account for this aspect by weighting the prey energy by its accessibility. Accessibility coefficients that were designed for this objective in Tableau et al. (2015) were therefore used in here. Accordingly, we used available energy data $\left(\mathrm{kJ} \cdot \mathrm{m}^{-2}\right)$ for the invertebrates, and biomass data $\left(\mathrm{mg} \cdot \mathrm{m}^{-2}\right)$ for their predators to characterise the spatial predator-prey interactions.

\subsection{Spatial analyses}

\subsubsection{Collocation of predators and prey}

Spatial indices are relevant tools to summarise spatial data and detect patterns of predator and prey distributions (Bez et al., 1997). The global index of collocation (GIC) quantifies the geographical match between two spatial distributions (Woillez et al., 2007). That index was used in this study to compare the fish and the benthic macro-invertebrate spatial distributions. The GIC ranges between 0 and 1 , wherein 1 means that the spatial overlap is high. Specifically, it compares the squared distance 
between the distributions' centres of gravity $\left(\Delta \mathrm{CG}^{2}\right)$, wherein a centre of gravity $(\mathrm{CG})$ is the mean location of a spatial distribution, and the squared mean distance between two individuals taken at random and independently from each spatial distribution $\left(\Delta C G^{2}+l_{1}+I_{2} ; I_{1}\right.$ and $I_{2}$ are the respective inertias of each spatial distribution; i.e., spatial standard deviation):

$G I C=1-\frac{\Delta C G^{2}}{\Delta C G^{2}+I_{1}+I_{2}}$

The inertia can be decomposed into its two main axes, corresponding to the standard deviation of the projection of the location of the distribution along the principal directions of dispersion (Woillez et al., 2007). The GIC can be represented graphically using the two main axes of inertia, wherein the intersection of the two axes corresponds to the distribution's centre of gravity (Fig. 2). The sampling design being spatially split into two sectors (because of unsampled rocky habitat; Fig. 2), inertia and centres of gravity of the predators and prey distributions would be driven more by this design than by the data. To overcome this problem, we computed two GICs, one for each sectors (north and south), and estimated the mean GIC. We used the mean GIC index to select the most appropriate organisational level of fish (species, morphological group, or community level) to quantify the spatial match between fish and their prey. Though GIC provides insight on the spatial relationship between predator and prey, it does not prove the statistical significance of that relationship.

\subsubsection{Ordinary kriging}

The spatial mismatch between the samplings of the fish (trawls) and their prey (grabs) led us to use interpolation methods. The first step consisted of fitting a variogram model (Matheron, 1971) to each dataset. Exponential, spherical, and linear models were considered with a nugget effect reflecting the variability in the data; the model with the best fit was chosen. Then, we kriged each dataset using Ordinary Kriging (Petitgas, 1996) to estimate biomass of predators $\left(Z^{*}{ }_{\text {fish }}\right)$ and available energy of prey $\left(Z_{\text {prey }}^{*}\right)$ at the scale of the Bay:

$Z^{*}=\sum_{\alpha} \lambda_{\alpha} \mathrm{Z}_{\alpha}$

where $\lambda_{\alpha}$ is the weight given by some decreasing function of the distance between the data to be estimated and the sampling data $\mathrm{Z}_{\alpha}$. We chose a moving neighbourhood for which i) the weight of the 
estimated mean of the map corresponded to a minimum in the estimation of the kriged points and ii) the average error ratio (i.e., the kriging mean over the samples mean) tended toward 1 (Petitgas, 1996). The estimation error was defined as:

$\sigma^{2}=C_{00}-\sum_{\alpha} \lambda_{\alpha} C_{\alpha 0}-\mu$

where $C_{00}$ is the covariance between two continuous estimated points, $\lambda_{\alpha}$ is the kriging weight for the sampling point $\alpha, C_{\alpha 0}$ is the covariance between the sampling point $\alpha$ and the kriged point, and $\mu$ is the Lagrange parameter.

The kriging grid was delimited on the intersection of the two dataset distributions (fish and macroinvertebrates); this intersection was defined as a polygon displayed on the Fig. 2. By using this polygon, the weight of the mean in the kriging was lower than the value of $1 / 2$, a value meaning that the estimation of kriged data was mainly driven by the sampled data. The mesh of the interpolation grid was set to $1 \mathrm{~km}$, as that value fell within the range of the distances between adjacent stations. The geostatistical analyses were performed using the RGeostats library (Renard et al., 2014) under the R environment (R Core Team, 2012).

\subsubsection{Testing the limiting factor hypothesis}

Using the kriged maps of both the predator and prey densities, we tested the food limitation hypothesis using quantile regressions. Quantile regression is consistent with the ecological concept of limiting factor (Cade et al., 1999; Hiddink and Kaiser, 2005) and is therefore suitable for testing our three scenarios on the food limiting influence on the fish distribution (Fig. 1). We tested the significance of the upper $\left(85^{\text {th }}, 90^{\text {th }}\right.$, and $\left.95^{\text {th }}\right)$ and lower $\left(5^{\text {th }}, 10^{\text {th }}\right.$, and $\left.15^{\text {th }}\right)$ quantiles and matched the results to one of the scenarios. If both quantiles were significant, then the data fit the first limiting-factor scenario (i.e., as described in the Introduction); if both quantile coefficients were not significant, then the data most likely fit the second scenario; if the upper quantile was significant but the lower quantile was not, then the data most likely corresponded to the third scenario.

Common methods for testing the significance of regression coefficients were not suitable here as we deliberately used the spatial structure of the data to interpolate values of predator biomass and prey available energy: the hypothesis of the independence of the data was obviously violated (Legendre 
and Legendre, 2012). Although a wide range of statistical adjustments was developed to counteract autocorrelation (Fortin and Payette 2002), they cannot be used with quantile regression as the theoretical distribution of the coefficient under the null hypothesis was unknown (Planque and Buffaz, 2008). One way to solve that problem was to use permutation tests where an empirical distribution of regression coefficients was constructed under a null hypothesis $\left(\mathrm{H}_{0}\right)$. Comparison between the observed regression coefficient and the empirical distribution under $\mathrm{H}_{0}$ was thus used to test the significance of the regression coefficient. The null hypothesis here was that "the observed relationship between the prey and predator distributions does not differ from the relationship between the prey and a randomly generated spatial distribution for the predators having the same properties as its observed distribution (i.e., the same number of observations, identical variogram structure, identical neighbourhood, and identical statistical distribution)". To build the empirical distribution of the regression coefficients under $\mathrm{H}_{0}$, geostatistical simulations were used to randomly generate many spatial distributions for the predators. These simulations were based on the variogram models derived from the three predator datasets and were non-conditional to the data points. These simulations were based on a normality assumption that needed to be checked beforehand in our datasets. The normality was observed on quantile-quantile plots and confirmed by a Kolmogorov-Smirnov test (the normality hypothesis was not rejected: $p$-value $>0.05)$ for the three predator datasets. We thus applied the procedure previously detailed to test the significance of upper and lower quantile coefficients and associated each response to one of the scenarios. Regression models were fit using the R package quantreg (Koenker, 2013). Empirical distributions were computed using 10000 simulations performed with the RGeostats library (Renard et al., 2014).

\section{RESULTS}

\subsection{Influence of the organisational level of fish predators}

The mean GIC between the prey distribution and the predator distributions were estimated for the three organisational levels (species, morphological group, and overall community; Table 2). The indices varied between 0.68 and 0.99 , with the highest values being associated with the community level. The estimated values were expected to be quite high because the samples were collected from a well-known nursery for fish species feeding on benthic invertebrates. The results underline that the 
larger the organisational level of predators, the higher the mean GIC value. If predators were actually distributed following the food availability, these results suggest that predators should be considered at the community level. However, as the difference between the GIC values of the community level and the two other organisational levels remained weak, it was meaningful to analyse the influence of the organisational level on the predator-prey relationship, considering the three levels.

\subsection{Mapping predators and prey distributions}

The variogram models for the three organisational levels of predators and for the prey were fitted to a maximum distance of $14 \mathrm{~km}$ (Appendix A). These four models were each fitted with i) a nugget effect; and ii) the best model from among the exponential, spherical, and linear type (Table 3). The interpolated maps (Fig. 3) were built by combining these variogram models to a moving neighbourhood with an influence radius of $4 \mathrm{~km}$; this value was selected to meet the criterion introduced in Materials and Methods. The kriging means and associated errors are given in Table 3. Error maps are provided in Appendix B.

The large range of values observed on all interpolated maps underlines the heterogeneity of the spatial distributions over the study area for both the prey and the predators. A visual comparison of the prey map with the $S$. Solea and flatfish maps suggests a good overlap in the south, in contrast to a poorer overlap in the north (Fig. 3). Predators considered at the community level display a better match with prey distributions, with notably a less productive sector (north-western area) contrasting with two relatively highly-productive sectors (mid-eastern and south-eastern areas). There are, however, small discrepancies between the two distribution maps, notably at the mouth of the estuary where the predators, whatever the organisational level, displayed medium values of biomass whereas the prey showed relatively low densities.

\subsection{Strength of the predator-prey relationship}

Quantitative comparison of the kriged distributions using upper quantile $\left(90^{\text {th }}\right)$ regressions clearly showed a positive relationship between predator and prey (Fig. 4), with points of high prey production corresponding to hotspots of predators. Positive slopes were observed for all predator organisational levels for the $90^{\text {th }}$ quantile. However, lower quantile $\left(10^{\text {th }}\right)$ regressions differed according to the organisational level; lower quantile slopes for $S$. solea and flatfish were close to 0 whereas the slope 
of the juvenile community was clearly positive. These relationships were confirmed statistically while accounting for the spatial autocorrelation of our data. The $90^{\text {th }}$ quantile regression coefficients were significantly positive for flatfish and community, but not for $S$. solea, though there was apparently a trend ( $p$-value < 0.1) (Table 3). Other upper quantiles were tested and also found to be significant for flatfish and for community (Table 3), suggesting a strong predator-prey relationship at those two levels. The coefficients of lower quantiles were only significant at the community level. The $5^{\text {th }}$ quantile for the community level was not significant and can be partly explained by the sensitivity of this quantile to outliers (Fig. 4).

When accounting for spatial autocorrelation, the test of the $50^{\text {th }}$ quantile corresponding to the centre of the distribution was significant for the community (Table 3); this was consistent with results of the upper and lower quantiles for this organisational level. Conversely, the $50^{\text {th }}$ quantile regression coefficient was not significant for the flatfish level though the upper quantile coefficient was significant. Regression analyses based only on the median effects was thus not an approach relevant to detect such a subtle trend (the limiting effects).

We also compared the $p$-values of the $50^{\text {th }}$ quantile regression that accounts for the spatial autocorrelation and usual ordinary least squares (OLS) regression that does not account for autocorrelation (i.e., linear model) for the three organisational levels. When the spatial structure was not taken into account, results were always highly significant: $p$-values $<0.0001$ (Table 3); otherwise, only the community level displayed significant results. This confirmed the importance of accounting for spatial dependency in statistical tests.

Taken together, these results supported the third scenario (i.e., positive correlation between food and juvenile fish densities, but only for the upper quantiles) (Fig. 1) for S. solea and flatfish levels, and the first scenario (i.e., positive correlation between food and juvenile fish densities) for the community level.

\section{DISCUSSION}

Wouters and Cabral (2009) suggested that coastal nursery grounds for benthic and demersal juvenile fish are richer in benthic invertebrate prey in comparison to other surrounding grounds. Since juveniles of many benthic and demersal fishes are distributed within those spatially limited habitats (Peterson et 
al., 2000; Beck et al., 2001; Fulford et al., 2011), their conclusion leads to an important question about the existence of a food limitation effect in nurseries. Interestingly, food availability is still rarely taken into account in explaining the distribution of benthic and demersal fishes (Johnson et al., 2013), although it seems to be a significant driver of fish spatial distribution (e.g., Selleslagh et al., 2012), especially for juvenile fishes (Vinagre et al., 2006; Le Pape et al., 2007). Most of the studies including prey as variables have been either conducted in the lab (e.g., Lindholm et al., 1999) or assessed at fine spatial scales (e.g., Sims et al., 2001), i.e. on the order of magnitude from $\mathrm{cm}^{2}$ to $\mathrm{m}^{2}$ (Johnson et al., 2013). The present study was undertaken at a broad geographic scale of over $200 \mathrm{~km}^{2}$ and quantified the spatial relationship between the densities of prey and predators considering different organisational levels (species, morphological groups, and community of predators). It provided two main results likely enhancing the knowledge on the functioning of soft-sediment coastal nursery habitats. First, juvenile fish generally followed the spatial distribution of their prey, and maybe exerted a strong predation pressure at the scale of the Bay. Second, the spatial predator-prey relationship was clearer and stronger by considering predators at the community level rather than at smaller organisational levels (S. solea and flatfish community levels). The following discussion attempts to interpret these results in the light of the knowledge existing on nursery ecosystem functioning. It also suggests hypotheses on the role of food availability on the spatial organisation of nursery habitats. Finally, we debate the contribution of these results to the food limitation hypothesis within coastal nursery habitats.

\subsection{Food availability and other factors affecting fish spatial distribution}

The spatial distribution of fish and their prey were more heterogeneous than expected over the Bay given the relative homogeneity of the environmental conditions (fine muddy sediments in $5-30 \mathrm{~m}$ depth: Burd et al., 2012). The prey energy density and the fish density, respectively, varied ten times and eight times across the Bay, with fish concentrating in the south-western and eastern sectors and largely absent in the north-western sector (see Fig. 3). Spatial distribution of fish species is commonly explained by both abiotic and biotic variables (Vinagre et al., 2006; Le Pape et al., 2007), while the relative contribution of those variables is possibly scale-dependent (see Johnson et al. (2013) for a review). Studies attempting to explain the distribution of juvenile fish using simple abiotic factors have underlined that a majority of the spatial variability (>60\%) remains unexplained (Abookire and 
Norcross, 1998; Le Pape et al., 2003; Trimoreau et al., 2013). For instance, Trimoreau et al. (2013) showed that salinity, depth, sediment type, and swell exposure explained together $14 \%, 24 \%$, and 5 $\%$ of the spatial distribution of $S$. solea, P. platessa, and D. cuneata in six nurseries of the Bay of Biscay, including the one examined in the present study. We also tried to model fish density using a set of available abiotic variables (depth, sediment granulometry, temperature, salinity), but no relationship was observed whatever the organisational level considered (unpublished results). Whether the set (or the scale) of environmental variables included in the model was unsuitable or that fish distribution is globally poorly predicted using abiotic variables at the scale of a nursery is difficult to assess. One certainty remains, the spatial organisation of juvenile fish in the Bay of Vilaine was well correlated with food availability given the current abiotic conditions.

\subsection{Predator-prey spatial relationships revealed at large organisational levels}

Predator-prey relationship is often studied between a single predator species and its associated prey (Collie, 1987; Hansson et al., 1996; Larsen and Guillemette, 2000; Hinz et al., 2005; Vinagre and Cabral, 2008; Johnson et al., 2012). However, interspecific food competition is especially strong among juvenile fish as their small mouths strongly limit their prey spectrum (Piet et al., 1998; Johnson et al., 2012). Several studies have shown that the feeding niche of benthic and demersal juvenile fishes, constituted of benthic macro-invertebrates, is often shared among the community of juveniles (e.g., Hamerlynck and Hostens, 1993; Darnaude et al., 2001; Vinagre and Cabral, 2008). Our results are in line with these studies as they showed that, when analysed at small organisational levels (the single flatfish species $S$. solea, and the flatfish group pooling three species), some sectors with high food availability seemed to be underutilised by flatfishes (i.e., significant upper quantiles). Conversely, pooling together flatfishes and roundfishes (community level) resulted in a higher collocation index, positive covariance for all the target quantiles, and a better spatial match between the predators and their prey. The feeding sectors poorly occupied by flatfishes (e.g., mid-eastern area) were then exploited by roundfishes. A sector with high feeding potential in the Bay seemed to have variable attractiveness to different fish species, but was always strongly exploited by a part of the fish community. We therefore hypothesise that food availability is a structuring factor in the distribution of the juvenile fish community in the Bay of Vilaine. 
The spatial occupancy of the community of predators suggests that the predation pressure on the macro-invertebrate community is possibly strong in the studied coastal nursery. This conclusion differs from the one of Collie (1987), and Vinagre and Cabral (2008), who stressed weak predation pressure of fish on benthic macro-invertebrates. Although these authors assessed differently the predation pressure, they acknowledged that considering only a part of the predators feeding on the same prey may have led to an underestimation of the predation pressure. Interestingly, the few studies that have accounted for most of epibenthic predators have concluded that strong predation pressure may exist (Evans, 1984; Pihl, 1985).

Food availability is suspected to have a major role in the distribution of juvenile fish in coastal nurseries (e.g., Gibson, 1994; Wouters and Cabral, 2009). However, the strength of that relationship has rarely been demonstrated. Using simulations, we attempted to understand why predator-prey relationships were clearer at the community level than at the species level (Appendix C). The simulation framework was based on the three assumptions: (1) each fish species has its own (abiotic) environmental niche (Hutchinson, 1953); (2) responses to food availability (biotic factor) are the same as the fishes share the same prey species, and; (3) the effects of abiotic and biotic factors are multiplicative because if one of them is degraded (e.g., hypoxic condition) in a sector, the fish will avoid that sector. Based on those assumptions we first simulated the spatial distribution of two fishes separately and then, the combined distribution (i.e. community). Visual comparison of the simulated maps and scatterplots corroborated the patterns observed in our study (Appendix C). At small organisational level (single fish species), only the upper limit in the fish-prey relationship was significant whereas the upper and lower limits were significant at large organisational level (combined distribution). Simulations suggest that the environmental effect might prevent from properly revealing the predator-prey relationship at the species level. The environment influence is drastically reduced when predator and prey are analysed at large organisational levels, as multiple species may tolerate a wider spectrum of (abiotic) environmental conditions. The nature of the predator-prey relationship can therefore be revealed without accounting for the specific effects of abiotic factors on individual species, and the strength of the relationship will likely be enhanced. 


\subsection{Why are juvenile fish concentrated on rich-food sectors?}

Rose and Leggett (1990) pointed out that spatial correlation between Atlantic cod (Gadus morhua) and its main prey, capelin (Mallotus villosus), was negative at small scales $(2-3 \mathrm{~km})$ but became positive at larger scales $(>4-10 \mathrm{~km})$. This shift was explained by two behaviours: prey escape at small scale and food search by predators at larger scales. Such negative correlation was not observed in the present study despite similar sampling scales. Indeed, benthic invertebrate movements can be considered negligible relative to those of juvenile fish. Indeed, unlike benthic macro-invertebrates, benthic and demersal juvenile fish can move up to $1 \mathrm{~km}$ daily and $10 \mathrm{~km}$ over several months (Riley, 1973; Gibson et al., 1998; Burrows et al., 2004; Vinagre et al., 2006; Le Pape and Cognez, 2015); thus, they can adjust their position according to their swimming ability. The positive spatial correlation observed with food in the current study can be explained either by the movement of fish towards sectors of high prey availability or to an indirect outcome in which a common abiotic environmental variable acted simultaneously on both the macro-invertebrate and fish communities. As mentioned earlier, no significant relationship was observed between fish density and a set of environmental variables (depth, sediment granulometry, temperature, salinity). We thus hypothesize that the positive correlation between fish and prey density corresponded to a causal relationship in which juvenile fish preferentially occupied the rich-food sectors of the nursery habitat.

Why would fish move towards rich-food sectors? Fish may optimise their energetic spending for foraging (Rose and Leggett, 1990) and/or food may be a limiting factor affecting fish survival. At first glance, some observations would lead us to conclude that simple fish behaviour is the primary structuring process, independent of food limitation: abundant fish was observed at the mouth of the Vilaine estuary where food availability was low. However, that subtidal sector is close to intertidal flats that are known to be rich in benthic invertebrates and to which juveniles migrate with the tide flow in order to feed (van der Veer et al., 1991; Rochette, 2011). That spatial discrepancy at the mouth of the estuary may be due to our sampling design, which precluded any sampling on intertidal flats. Hence, we cannot reject the possibility of food limitation to explain our predator-prey relationship in the Bay of Vilaine. 


\section{CONCLUSION}

The aim of this study was to assess the influence of benthic prey availability on the spatial distribution of benthic and demersal juvenile fish in a nursery ground. We showed that juveniles generally followed the spatial distribution of their prey and that this spatial predator-prey relationship was clearer and stronger by considering predators at the community level rather than at smaller organisational levels. Whether food is limiting fish survival in the nursery under study is far beyond the scope of our results. For instance, our results could be partly explained by behavioural responses to optimise energetic expenditures associated with foraging. However, the strong spatial relationships that our analyses have shown between the fish distribution and food availability, established at a large organisational level, provides an original way of analysing predator-prey relationships in a food limitation context.

\section{ACKNOWLEDGEMENTS}

Authors would like to thank Lucille Grimaud and Alexandre Mahuas for their technical help in sorting macrobenthos and analysing gut contents, and the crew of the Research Vessel Gwen-Drez during the Nurse scientific surveys of 2008. They also would like to thank Pierre Petitgas for his advice in geostatistics, and Tim Loher and the anonymous reviewers for their fruitful advice to improve the manuscript. 


\section{LITERATURE CITED}

Able KW. 2005. A re-examination of fish estuarine dependence: Evidence for connectivity between estuarine and ocean habitats. Estuar. Coast. Shelf Sci. 64: 5-17.

Abookire AA, Norcross BL. 1998. Depth and substrate as determinants of distribution of juvenile flathead sole (Hippoglossoides elassodon) and rock sole (Pleuronectes bilineatus), in Kachemak Bay, Alaska. J. Sea Res. 39: 113-123.

Amara R, Laffargue P, Dewarumez JM, Maryniak C, Lagardére F, Luzac C. 2001. Feeding ecology and growth of O-group flatfish (sole, dab and plaice) on a nursery ground (Southern Bight of the North Sea). J. Fish Biol. 58: 788-803.

Amara R, Mahé K, Le Pape O, Desroy N. 2004. Growth, feeding and distribution of the solenette Buglossidium luteum with particular reference to its habitat preference. J. Sea Res. 51: 211-217. Beck MW, Heck KL, Able KW, Childers DL, Eggleston DB, Gillanders BM, Halpern BS, Hays CG, Hoshino K, Minello TJ, Orth RJ, Sheridan PF, Weinstein MP. 2001. The identification, conservation, and management of estuarine and marine nurseries for fish and invertebrates. Bioscience 51: 633641.

Bez N, Rivoirard J, Guiblin P, Walsh M. 1997. Covariogram and related tools for structural analysis of fish survey data. Geostatistics Wollongong '96 Kluwer, Dordrecht: Springer Science \& Business Media. p. 1316.

Brey T. 2001. Population dynamics in benthic invertebrates. A virtual handbook. Version 01.2. http://www.thomas-brey.de/science/

Brey T, Mueller-Wiegmann C, Zittier ZMC, Hagen W. 2010. Body composition in aquatic organisms - A global data bank of relationships between mass, elemental composition and energy content. J. Sea Res. 64: 334-340.

Brind'Amour A, Laffargue P, Morin J, Vaz S, Foveau A, Le Bris H. 2014. Morphospecies and taxonomic sufficiency of benthic megafauna in scientific bottom trawl surveys. Cont. Shelf Res. 72: 19. 
Brind'Amour A, Rouyer A, Martin J. 2009. Functional gains of including non-commercial epibenthic taxa in coastal beam trawl surveys: A note. Cont. Shelf Res. 29: 1189-1194.

Burd BJ, Macdonald TA, van Roodselaar A. 2012. Towards predicting basin-wide invertebrate organic biomass and production in marine sediments from a coastal sea. PloS one 7: e40295.

Burrows MT, Gibson RN, Robb L, Comely CA. 1994. Temporal patterns of movement in juvenile flatfishes and their predators: underwater television observations. J. Exp. Mar. Biol. Ecol. 177: 251268.

Burrows MT, Gibson RN, Robb L, Maclean A. 2004. Alongshore dispersal and site fidelity of juvenile plaice from tagging and transplants. J. Fish Biol. 65: 620-634.

Cade BS, Terrell JW, Schroeder RL. 1999. Estimating effects of limiting factors with regression quantiles. Ecology 80: 311-323.

Collie JS. 1987. Food-consumption by yellowtail flounder in relation to production of its benthic prey. Mar. Ecol. Prog. Ser. 36: 205-213.

Darnaude AM, Harmelin-Vivien MI, Salen-Picard C. 2001. Food partitioning among flatfish (Pisces: Pleuronectiforms) juveniles in a Mediterranean coastal shallow sandy area. J. Mar. Biol. Assoc. U. K. 81: 119-127.

Desaunay Y, Perddou JB, Beillois P. 1981. Etude des nurseries de poissons du littoral de la LoireAtlantique. Science et Pêche 319: 1-23.

Desmarchelier M. 1986. Contribution à l'étude de la biologie des populations de Tacauds Trisopterus luscus (L.1758) en Manche orientale et dans le sud de la Mer du Nord. Université des Sciences et Techniques de Lille.

Dorel D, Koutsikopoulos C, Desaunay Y, Marchand J. 1991. Seasonal distribution of young sole (Solea solea (L.)) in the nursery ground of the bay of Vilaine (Northern bay of Biscay). Neth. J. Sea Res. 27: 297-306.

Eleftheriou A, Mclntyre A. 2005. Methods for the Study of Marine Benthos. Oxford: Blackwell Science. Elliott M, Hemingway K. 2002. Fishes in Estuaries. Oxford: Blackwell Science. 
Evans S. 1984. Energy budgets and predation impact of dominant epibenthic carnivores on a shallow soft bottom community at the Swedish west coast. Estuar. Coast. Shelf Sci. 18: 651-672.

Fortin MJ, Payette S. 2002. How to test the significance of the relation between spatially autocorrelated data at the landscape scale: A case study using fire and forest maps. Ecoscience 9: 213-218.

Franco A, Franzoi P, Malavasi S, Riccato F, Torricelli P. 2006. Fish assemblages in different shallow water habitats of the Venice Lagoon. Hydrobiologia 555: 159-174.

Fulford RS, Peterson MS, Grammer PO. 2011. An ecological model of the habitat mosaic in estuarine nursery areas: Part I-Interaction of dispersal theory and habitat variability in describing juvenile fish distributions. Ecol. Model. 222: 3203-3215.

Gallardo VA. 1965. Observations on the biting profiles of three $0.1 \mathrm{~m} 2$ bottom-samplers. Ophelia 2: 319-322.

Gibson R. 1994. Impact of habitat quality and quantity on the recruitment of juvenile flatfishes. Neth. J. Sea Res. 32: 191-206.

Gibson RN, Pihl L, Burrows MT, Modin J, Wennhage H, Nickell LA. 1998. Diel movements of juvenile plaice Pleuronectes platessa in relation to predators, competitors, food availability and abiotic factors on a microtidal nursery ground. Mar. Ecol. Prog. Ser. 165: 145-159.

Hamerlynck O, Hostens K. 1993. Growth, feeding, production, and consumption in 0-group bib (Trisopterus luscus L.) and whiting (Merlangius merlangus L.) in a shallow coastal area of the southwest Netherlands. ICES J. Mar. Sci.: Journal du Conseil 50: 81-91.

Hampel H, Cattrijsse A, Elliott M. 2005. Feeding habits of young predatory fishes in marsh creeks situated along the salinity gradient of the Schelde estuary, Belgium and The Netherlands. Helgoland Mar. Res. 59: 151-162.

Hansson S, Rudstam LG, Kitchell JF, Hilden M, Johnson BL, Peppard PE. 1996. Predation rates by North Sea cod (Gadus morhua) - Predictions from models on gastric evacuation and bioenergetics. ICES J. Mar. Sci. 53: 107-114. 
Hiddink JG, Kaiser MJ. 2005. Implications of Liebig's law of the minimum for the use of ecological indicators based on abundance. Ecography 28: 264-271.

Hinz H, Kroencke I, Ehrich S. 2005. The feeding strategy of dab Limanda limanda in the southern North Sea: linking stomach contents to prey availability in the environment. J. Fish Biol. 67: 125-145.

Hutchinson GE. 1953. The concept of pattern in ecology. Proc. Acad. Nat. Sci. 105: 1-12.

Johnson AF, Jenkins SR, Hiddink JG, Hinz H. 2013. Linking temperate demersal fish species to habitat: scales, patterns and future directions. Fish and Fish. 14: 256-280.

Johnson AF, Valls M, Moranta J, Jenkins SR, Hiddink JG, Hinz H. 2012. Effect of prey abundance and size on the distribution of demersal fishes. Can. J. Fish. Aquat. Sci. 69: 191-200.

Juanes F, Conover DO. 1994. Piscivory and prey size selection in young-of-the-year bluefish: predator preference or size-dependent capture success? Mar. Ecol. Prog. Ser. 114: 59-69.

Koenker R. 2013. quantreg: Quantile Regression. R package version 5.05. http://CRAN.Rproject.org/package=quantreg

Kopp D, Le Bris H, Grimaud L, Nerot C, Brind'Amour A. 2013. Spatial analysis of the trophic interactions between two juvenile fish species and their preys along a coastal-estuarine gradient. J. Sea Res. 81: 40-48.

Kostecki C, Le Loc'h F, Roussel J-M, Desroy N, Huteau D, Riera P, Le Bris H, Le Pape O. 2010. Dynamics of an estuarine nursery ground: the spatio-temporal relationship between the river flow and the food web of the juvenile common sole (Solea solea, L.) as revealed by stable isotopes analysis. J. Sea Res. 64: 54-60.

Larsen JK, Guillemette M. 2000. Influence of annual variation in food supply on abundance of wintering common eiders Somateria mollissima. Mar. Ecol. Prog. Ser. 201: 301-309.

Legendre P, Legendre L. 2012. Numerical Ecology. Elsevier, Oxford.

Le Bris H, Glemarec M. 1995. Macrozoobenthic communities of an oxygen under-saturated coastal ecosystem: The Bay of Vilaine (Southern Brittany). Oceanol. Acta 18: 573-581. 
Le Pape O, Baulier L, Cloarec A, Martin J, Le Loc'h F, Désaunay Y. 2007. Habitat suitability for juvenile common sole (Solea solea, L.) in the Bay of Biscay (France): A quantitative description using indicators based on epibenthic fauna. J. Sea Res. 57: 126-136.

Le Pape O, Bonhommeau S. 2015. The food limitation hypothesis for juvenile marine fish. Fish and Fish. 16: 373-398.

Le Pape O, Chauvet F, Desaunay Y, Guerault D. 2003. Relationship between interannual variations of the river plume and the extent of nursery grounds for the common sole (Solea solea, L.) in Vilaine Bay. Effects on recruitment variability. J. Sea Res. 50: 177-185.

Le Pape O, Cognez N. 2015. The range of juvenile movements of estuarine and coastal nursery dependent flatfishes: estimation from a meta-analytical approach. J. Sea Res. (Handling Editor's note: insert issue number and page range when layout of this issue has been completed)

Lindholm JB, Peter JA, Kaufman LS. 1999. Habitat-mediated survivorship of juvenile (0-year). Mar. Ecol. Prog. Ser. 180: 247-255.

Marchand J. 1991. The influence of environmental conditions on settlement, distribution and growth of 0-group sole (Solea solea (L.)) in a macrotidal estuary (Vilaine, France). Neth. J. Sea Res. 27: 307316.

Matheron G. 1971. The theory of regionalized variable and its applications. Fontainebleau: Centre de Geostatistique.

Morrison MA, Francis MP, Hartill BW, Parkinson DM. 2002. Diurnal and Tidal Variation in the Abundance of the Fish Fauna of a Temperate Tidal Mudflat. Estuar. Coast. Shelf Sci. 54: 793-807. Nash RDM, Geffen AJ. 2000. The influence of nursery ground processes in the determination of yearclass strength in juvenile plaice Pleuronectes platessa L. in Port Erin Bay, Irish Sea. J. Sea Res. 44: $101-110$.

Nicolas D, Le Loc'h F, Desaunay Y, Hamon D, Blanchet A, Le Pape O. 2007. Relationships between benthic macrofauna and habitat suitability for juvenile common sole (Solea solea, L.) in the Vilaine estuary (Bay of Biscay, France) nursery ground. Estuar. Coast. Shelf Sci. 73: 639-650. 
Pasquaud S, Béguer M, Larsen MH, Chaalali A, Cabral H, Lobry J. 2012. Increase of marine juvenile fish abundances in the middle Gironde estuary related to warmer and more saline waters, due to global changes. Estuar. Coast. Shelf Sci. 104-105: 46-53.

Peterson $\mathrm{CH}$, Summerson HC, Thomson E, Lenihan HS, Grabowski J, Manning L, Micheli F, Johnson G. 2000. Synthesis of linkages between benthic and fish communities as a key to protecting essential fish habitat. Bull. Mar. Sci. 66: 759-774.

Petitgas P. 1996. Geostatistics and their applications to fisheries survey data. Computers in Fisheries Research London: Chapman \& Hall. p. 113-142.

Piet GJ, Pfisterer AB, Rijnsdorp AD. 1998. On factors structuring the flatfish assemblage in the southern North Sea. J. Sea Res. 40: 143-152.

Pihl L. 1985. Food selection and consumption of mobile epibenthic fauna in shallow marine areas. Mar. Ecol. Prog. Ser. 22: 169-179.

Planque B, Buffaz L. 2008. Quantile regression models for fish recruitment-environment relationships: four case studies. Mar. Ecol. Prog. Ser. 357: 213-223.

R Core Team. 2012. R: A Language and Environment for Statistical Computing. Vienna, Austria: R Foundation for Statistical Computing.

Renard D, Bez N, Desassis N, Beucher H, Ors F, Laporte F. 2014. RGeoS: The Geostatistical package. Mines ParisTech.

Rijnsdorp AD, Van Beek FA, Flatman S, Millner RM, Riley JD, Giret M, De Clerck R. 1992.

Recruitment of sole stocks, Solea solea (L.), in the Northeast Atlantic. Neth. J. Sea Res. 29: 173-192.

Riley JD. 1973. Movements of 0-group plaice Pleuronectes platessa L. as shown by latex tagging. J. Fish Biol. 5: 323-343.

Rochette S. 2011. Effet des perturbations anthropiques sur la survie des juvéniles de poissons marins dans les nourriceries et conséquences sur le renouvellement des populations. Application au stock de sole commune (Solea solea) en Manche Est. Agrocampus Ouest, Rennes. 
Rochette S, Rivot E, Morin J, Mackinson S, Riou P, Le Pape O. 2010. Effect of nursery habitat degradation on flatfish population: Application to Solea solea in the Eastern Channel (Western Europe). J. Sea Res. 64: 34-44.

Rogers SI. 1992. Environmental factors affecting the distribution of sole (Solea solea (L.)) within a nursery area. Neth. J. Sea Res. 29: 153-161.

Rogers SI. 1994. Population density and growth rate of juvenile sole Solea solea (L.). Neth. J. Sea Res. 32: 353-360.

Rose GA, Leggett WC. 1990. the importance of scale to predator-prey spatial correlations: An example of Atlantic fishes. Ecology 71: 33-43.

Seitz RD, Wennhage H, Bergström U, Lipcius RN, Ysebaert T. 2014. Ecological value of coastal habitats for commercially and ecologically important species. ICES J. Mar. Sci.: Journal du Conseil 71 : 648-665.

Selleslagh J, Lobry J, N'Zigou AR, Bachelet G, Blanchet H, Chaalali A, Sautour B, Boët P. 2012. Seasonal succession of estuarine fish, shrimps, macrozoobenthos and plankton: Physico-chemical and trophic influence. The Gironde estuary as a case study. Estuar. Coast. Shelf Sci. 112: 243-254. Sims D, Nash J, Morritt D. 2001. Movements and activity of male and female dogfish in a tidal sea lough: alternative behavioural strategies and apparent sexual segregation. Mar. Biol., 139: 1165-1175. Tableau A, Le Bris H, Brind'Amour A. 2015. Available Benthic Energy Coefficient (ABEC): a generic tool to estimate the food profitability in coastal fish nurseries. Mar. Ecol. Prog. Ser. 522: 203-218. Trimoreau E, Archambault B, Brind'Amour A, Lepage M, Guitton J, Le Pape O. 2013. A quantitative estimate of the function of soft-bottom sheltered coastal areas as essential flatfish nursery habitat. Estuar. Coast. Shelf Sci. 133: 193-205.

Van der Veer HW, Bergman M. J. N., Dapper R, Witte Jl. 1991. Population dynamics of an intertidal 0group flounder Platichthys flesus population in the western Dutch Wadden Sea. Mar. Ecol. Prog. Ser. 73: $141-148$. 
Van der Veer HW, Freitas V, Koot J, Witte JI, Zuur AF. 2010. Food limitation in epibenthic species in temperate intertidal systems in summer: analysis of 0-group plaice Pleuronectes platessa. Mar. Ecol. Prog. Ser. 416: 215-227.

Van der Veer HW, Geffen AJ, Witte JIJ. 2000. Exceptionally strong year classes in plaice Pleuronectes platessa: are they generated during the pelagic stage only, or also in the juvenile stage? Mar. Ecol. Prog. Ser. 199: 255-262.

Van der Veer HW, Witte JIJ. 1993. The Maximum Growth Optimal Food Condition Hypothesis - a Test for 0-Group Plaice Pleuronectes-Platessa in the Dutch Wadden Sea. Mar. Ecol. Prog. Ser. 101: 8190.

Van Veen J. 1933. Onderzoeknaar het zandtransport von rivieren. De Ingenieur 48: 151-159.

Vinagre C, Cabral HN. 2008. Prey consumption by the juvenile soles, Solea solea and Solea senegalensis, in the Tagus estuary, Portugal. Estuar. Coast. Shelf Sci. 78: 45-50.

Vinagre C, França S, Cabral HN. 2006. Diel and semi-lunar patterns in the use of an intertidal mudflat by juveniles of Senegal sole, Solea senegalensis. Estuar. Coast. Shelf Sci. 69: 246-254.

Woillez M, Poulard J-C, Rivoirard J, Petitgas P, Bez N. 2007. Indices for capturing spatial patterns and their evolution in time, with application to European hake (Merluccius merluccius) in the Bay of Biscay. ICES J. Mar. Sci.: Journal du Conseil 64: 537-550.

Wouters N, Cabral HN. 2009. Are flatfish nursery grounds richer in benthic prey? Estuar. Coast. Shelf Sci. 83: 613-620. 


\section{FIGURES}
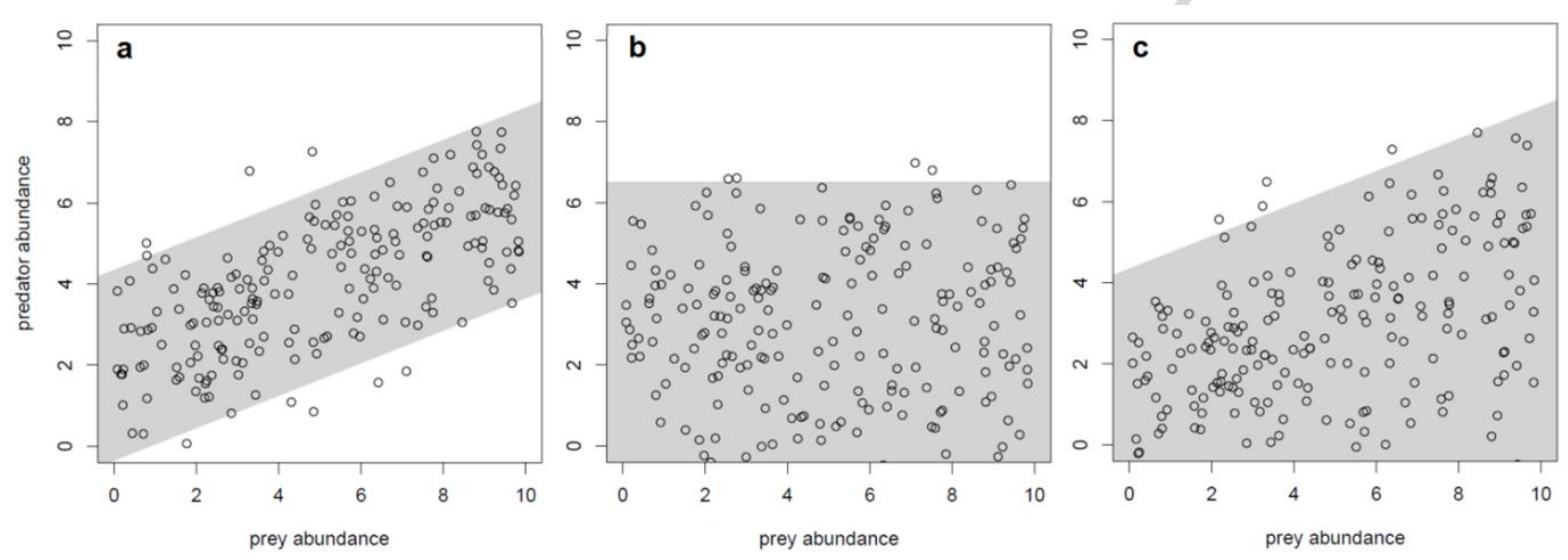

Fig. 1: Graphical description of the three scenarios used to infer the strength of the food limitation hypothesis in explaining juvenile fish distribution within nursery habitat (simulated data). (a) Prey density is the main factor influencing the spatial distribution of the predators. Natural variability constitutes the noise (variability) in the signal. (b) Prey density is independent of the predator density; in this scenario, food is not limiting. (c) Prey density partially regulates the predator spatial distribution, but other unmeasured factors seem also to be locally-limiting. 


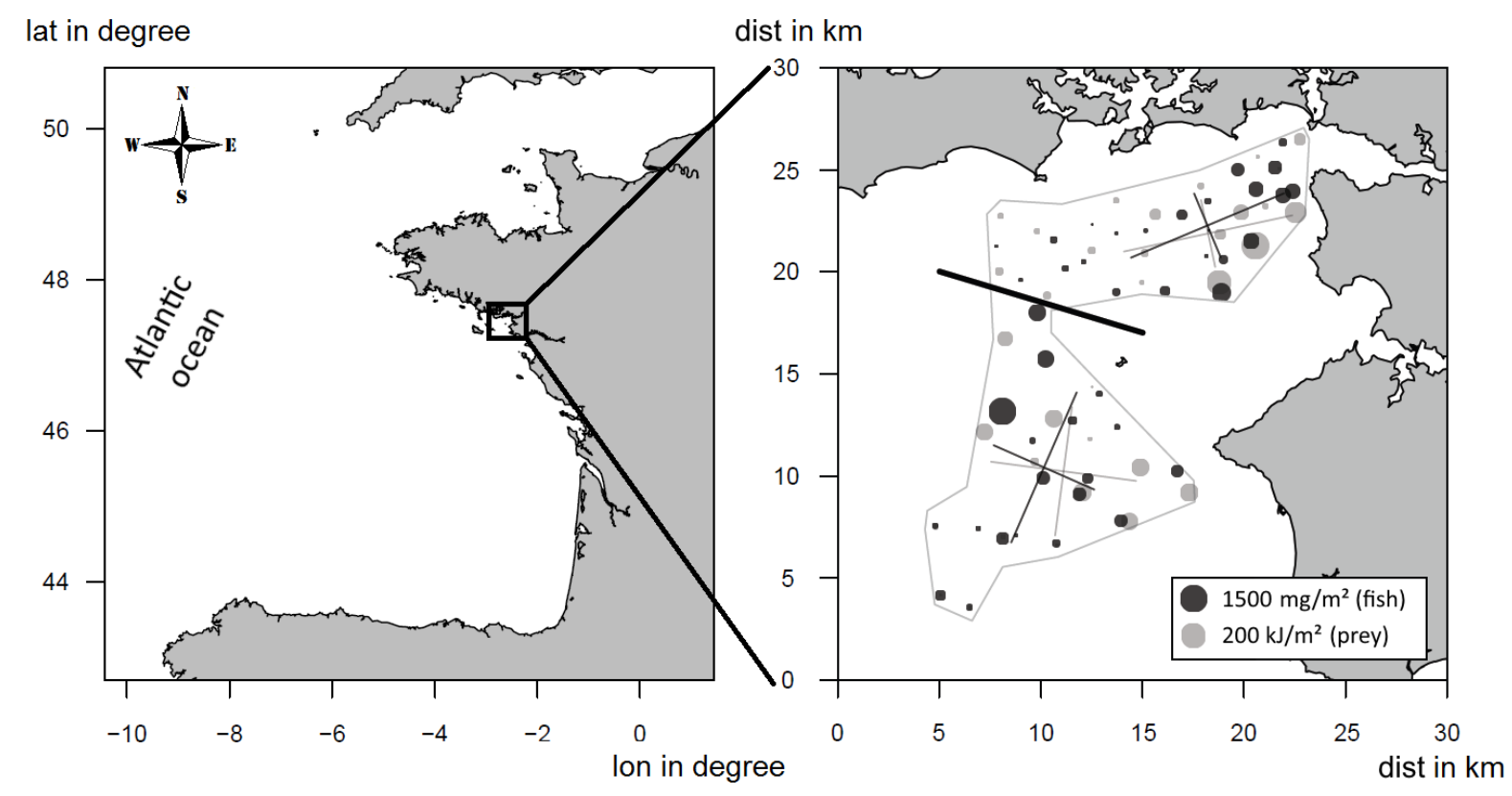

Fig. 2: The Bay of Vilaine and the sampling area delimited by a spatial polygon (the c-shape is due to a non-sampled rocky shelf that occupies the East of the Bay). Dark and light grey circles are proportional to fish predator and prey densities respectively. Dark and light grey crosses indicate the centres of gravity and the axes of inertia in each sector (north and south), of the predators and their prey, respectively (see Methods for details). The dark line in the right-hand panel indicates the boundary between the north and south sectors, which are separated because of the c-shape of the sampling zone. 

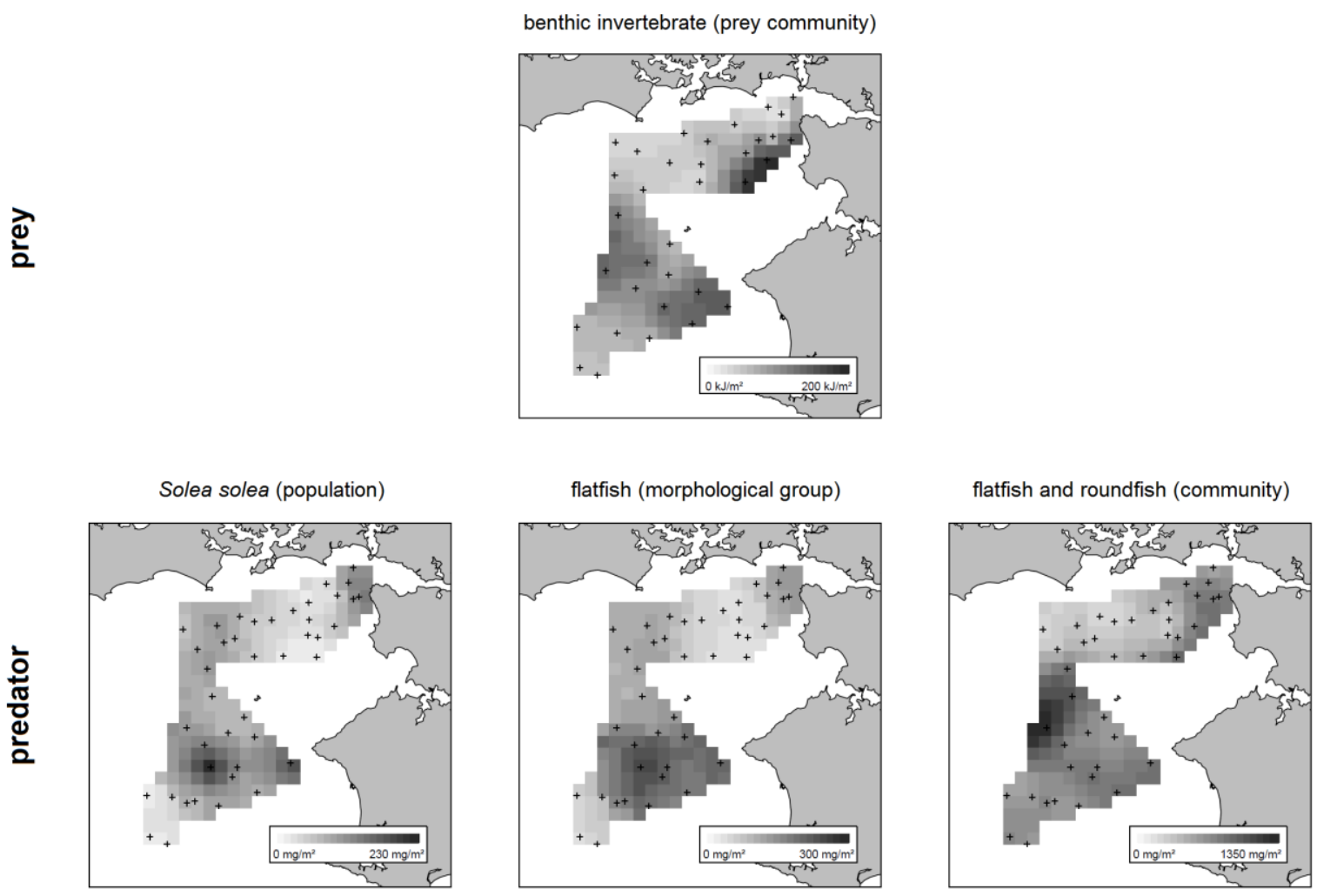

Fig. 3: Distribution maps of the accessible prey energy (top box) and the predator biomass following different levels of organisation ranging from species (Solea solea) to community (flatfish and roundfish). 

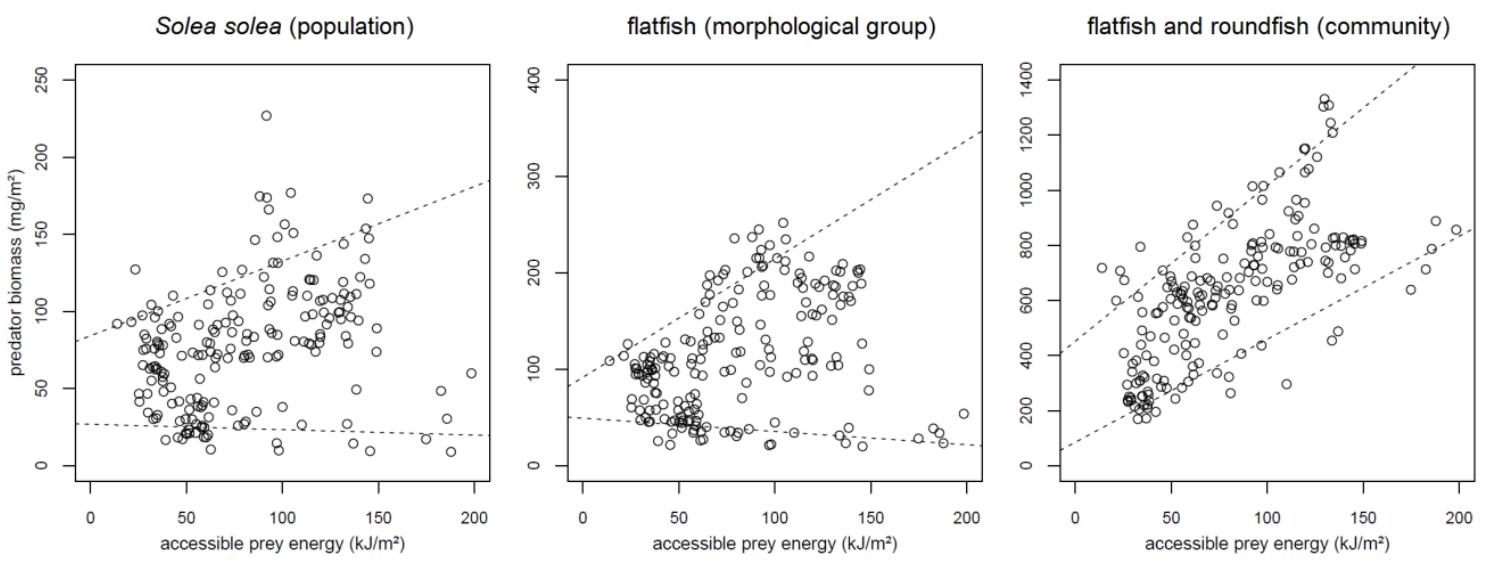

Fig.4: Scatterplots of predator biomass as a function of prey energy, for each of three levels of predator organisation (i.e., single-species, flatfish, and community). Upper and lower dashed lines correspond respectively to the quantile regressions 0.1 and 0.9 . 


\section{TABLES}

Table 1: Observed and selected size range for G0 and G1 juveniles. *: species for which the selected size differs from the observed size

\begin{tabular}{l|cc|cc}
\multirow{2}{*}{ species } & \multicolumn{2}{|c|}{ observed size range } & \multicolumn{2}{c}{ selected size range } \\
\cline { 2 - 5 } & $\begin{array}{l}\min \text { size } \\
\text { (in cm) }\end{array}$ & $\begin{array}{c}\max \text { size } \\
\text { (in cm) }\end{array}$ & $\begin{array}{c}\text { threshold size } \\
\text { (in cm) }\end{array}$ & $\begin{array}{c}\text { ceiling size } \\
\text { (in cm) }\end{array}$ \\
\hline Dicologlossa cuneata & 11 & 22 & 11 & 22 \\
Pleuronectes platessa & 6 & 11 & $7^{*}$ & 11 \\
Solea solea & 7 & 21 & 7 & 21 \\
Callionymus lyra & 4 & 15 & $7^{*}$ & 15 \\
Merlangius merlangus & 5 & 23 & $7^{*}$ & $15^{*}$ \\
Mullus surmuletus & 5 & 11 & $7^{*}$ & 11 \\
Trisopterus luscus & 3 & 35 & $7^{*}$ & $15^{\star}$
\end{tabular}


Table 2: Global index of collocation (GIC) between the accessible prey energy and the predator biomass following different organisational levels.

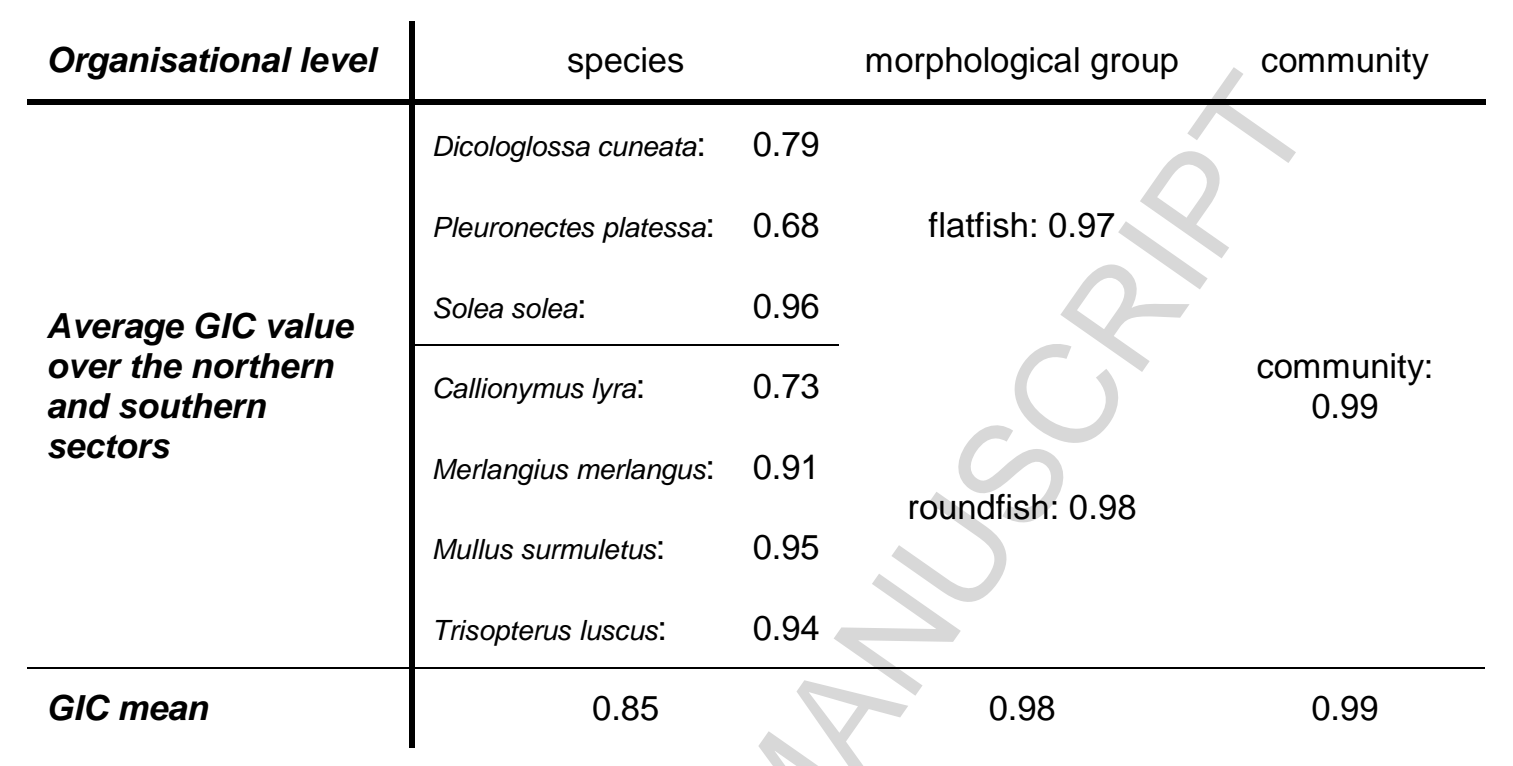


Table 3: Parameter values of the kriged maps (parts 1 and 2), the $p$-values of the different correlation tests between the different organisational levels of predators and prey (parts 3 and 4); *: p-value < 0.05 .

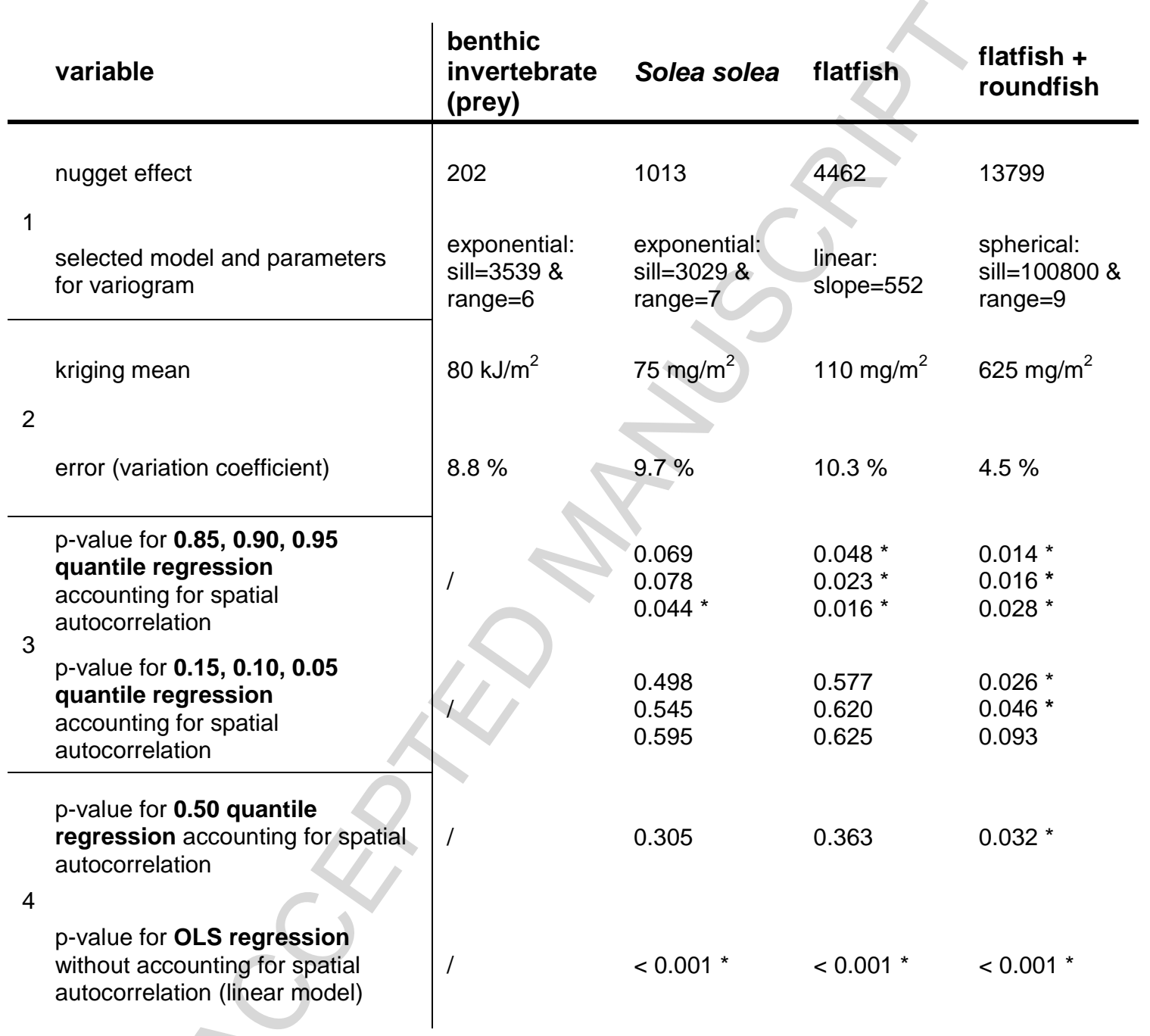




\section{Appendix A : Fitted variograms of the predators and the prey}
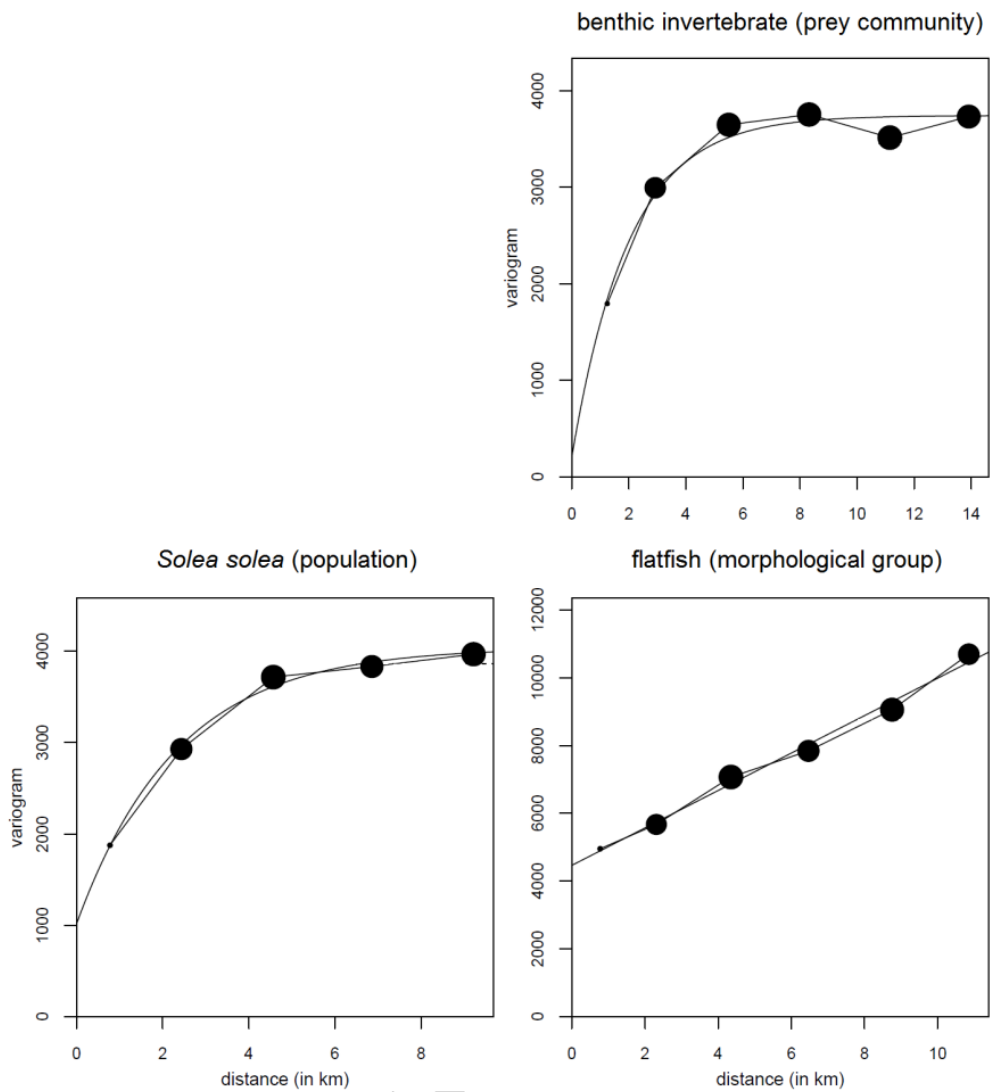

flatfish and roundfish (community)

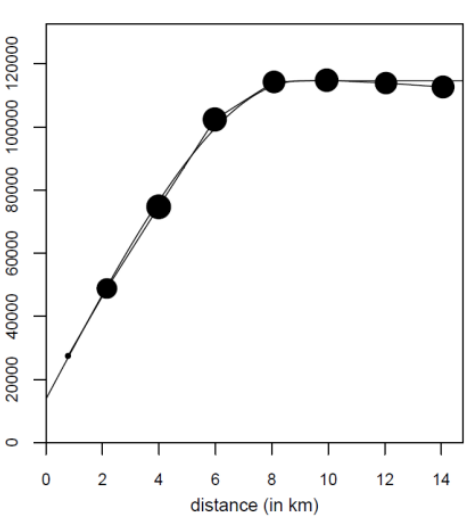

Figure A1: Fitted experimental variograms for prey (top box) and fish predator following different organisational levels (respectively Solea solea, flatfish, flatfish and roundfish). The size of the circles is proportional to the number of pairs of data points involved in the computation of the corresponding distance lag (between 50 and 220 pairs for each point except for the first one). 


\section{Appendix B : Error distribution maps for the predators and the prey}

benthic invertebrate (prey community)

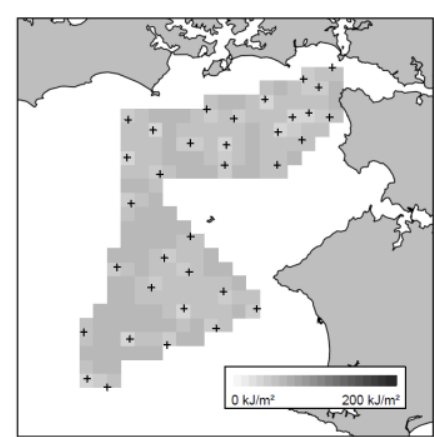

Solea solea (population)

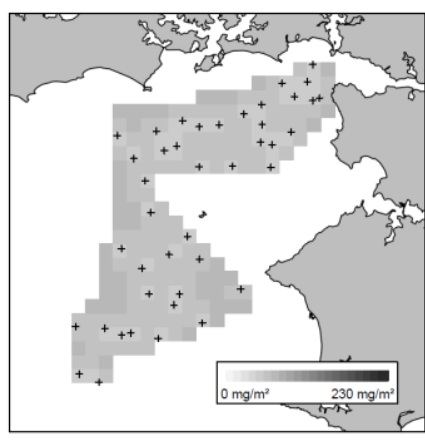

flatfish (morphological group)

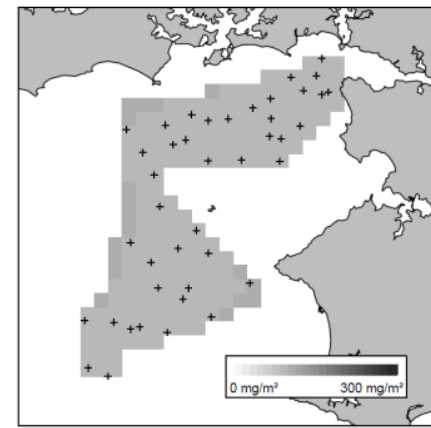

flatfish and roundfish (community)

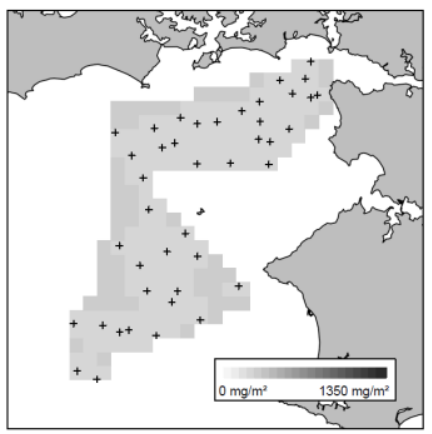

Figure B1: Error distribution maps of the accessible prey energy (top box) and the predator biomass following different organisational levels, from species (Solea solea) to community (flatfish and roundfish). 


\section{Appendix C : Simulations of food availability and abiotic factors in species spatial distribution}

A simulation framework was develop to assess the relative contribution of abiotic (e.g., salinity) and biotic (food availability) variables in different organisational levels (Figure C1). The simulations used the methodology that follows A) We first simulated two maps corresponding to an environmental gradient (e.g., salinity) and a distribution of a pool of prey shared by two fishes. B) We defined the fish response to each factor (environment and food) with a two first assumptions: each fish had its own (abiotic) environmental niche, and whatever the fish species, where more food was available, fish density was greatest. C) A third assumption was that the probability of fish being present at any point on the map was the product of the two factor effects (i.e., abiotic and biotic). D) The spatial distributions of each fish and the higher organisational group, pooling those two fishes, were simulated directly from the equation accounting from the two factors ; E) from a data sampling on the surface area, the fish population densities were displayed as functions of prey density. From this analysis, we observed that the nature of the fish response to the food availability was clearly identified by considering them at the largest organisational group (fish $1+$ fish 2); the reason for this is that, whatever the environment conditions at a given location, one or another of fish species considered is able to occupy the associated sectors. 


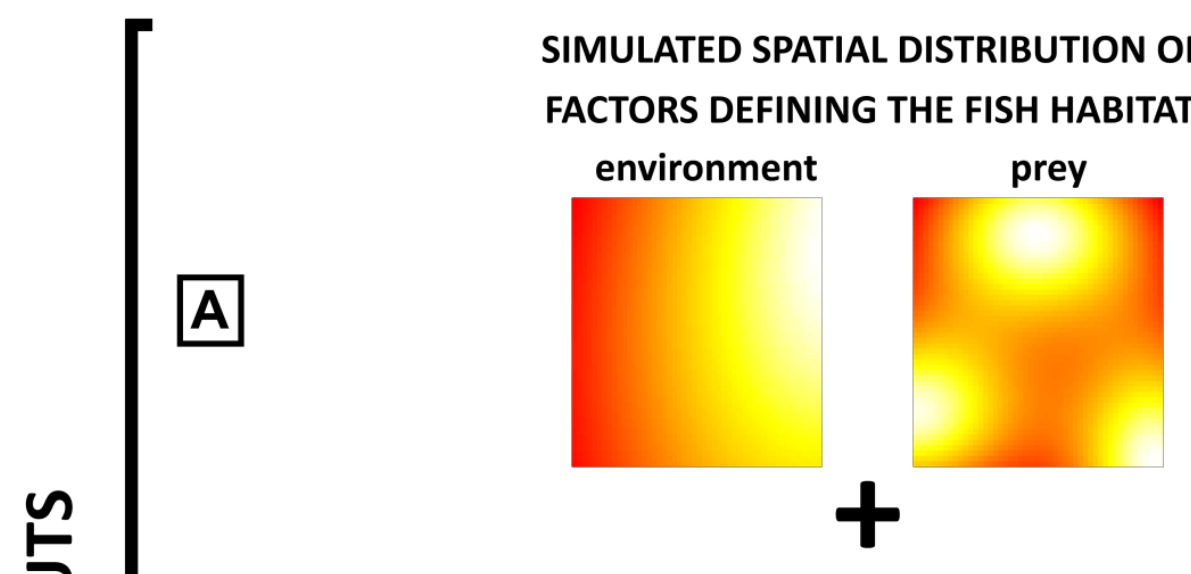

FISH RESPONSE TO EACH FACTOR
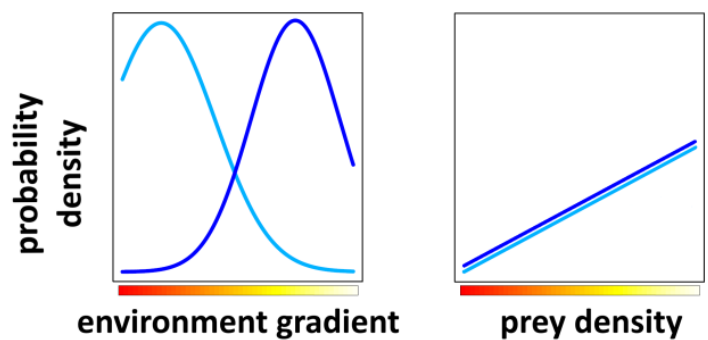

- fish 1

B

eq. 1
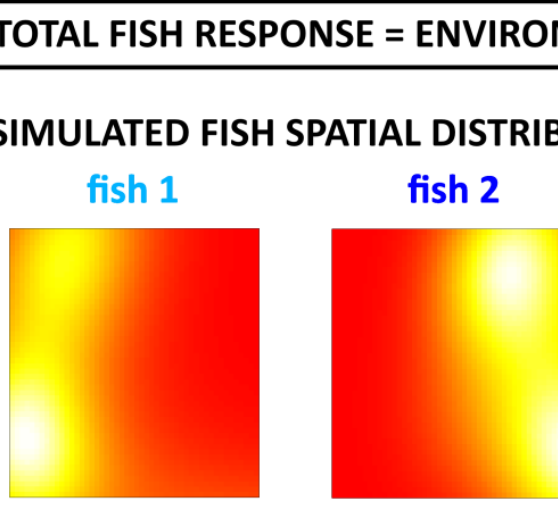

\section{RELATIONSHIP}
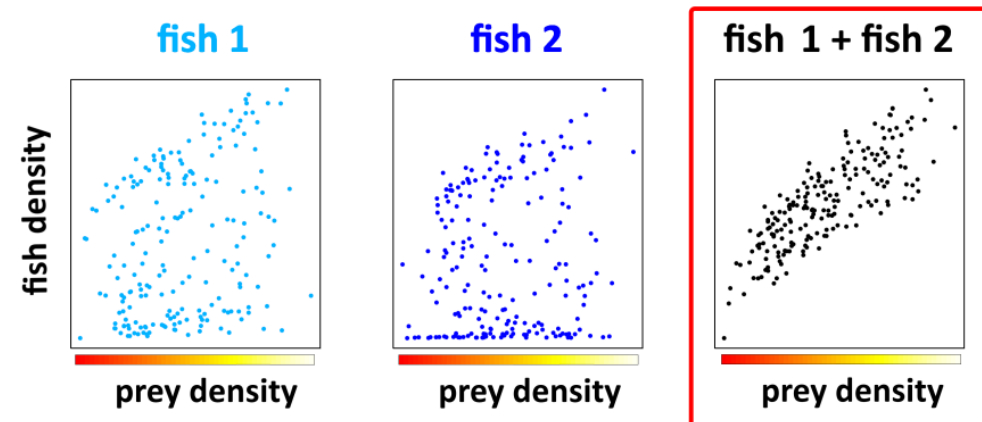

The nature of the fish-prey spatial relationship is revealed by considering the largest organisational level 
Figure $\mathrm{C} 1$ : Simulation schemes (inputs) and results (outputs) highlighting that at small organisational level (fish species), only the upper limit in the fish-prey relationship is significant, whereas the upper and lower limits are significant at large organisational level (fish $1+$ fish 2). The simulations suggest that the variability induced by the environment appears as noise when the predator-prey relationship is analysed at the species level. That noise is drastically reduced when predator and prey are analysed at a larger organisational level, as multiple species may tolerate a wider spectrum of (abiotic) environmental conditions than either individual species. 